Review

\title{
Carbon Assimilation, Biomass Partitioning and Productivity in Grasses
}

\section{Louis J. Irving}

Faculty of Life and Environmental Science, University of Tsukuba, 1-1-1 Tennodai, Tsukuba 305-8572, Japan; E-Mail: irving.louis.fb@u.tsukuba.ac.jp; Tel.: +81-029-853-4777

Academic Editor: Cory Matthew

Received: 10 September 2015 / Accepted: 29 October 2015 / Published: 10 November 2015

\begin{abstract}
Plant growth correlates with net carbon gain on a whole plant basis. Over the last several decades, the driving factors shaping plant morphology and performance have become increasingly clear. This review seeks to explore the importance of these factors for grass performance. Briefly, these fall into factors influencing photosynthetic rates directly, competition between plants in a canopy, and nutrient status and availability.
\end{abstract}

Keywords: carbon; nitrogen; biomass partitioning; shoot-root allocation

\section{Introduction}

Plant growth correlates with net carbon (C) gain on a whole plant basis [1]. Photosynthetic rates vary between species, but leaf nitrogen $(\mathrm{N})$ content and light intensity are known to be major determinants [2]. The other main factor determining plant carbon gain is leaf area per plant, which is a function of mean leaf area and leaf number. In grasses, the production of secondary stems by tillering can greatly increase leaf number per plant, with tiller numbers appearing to be mediated by plant nutrient status, light availability and competition for light between plants in a stand.

A recent review [3] looked at the factors controlling the allocation of biomass to leaves, stems, and roots in a wide range of species. The most important factors were determined to be the quantity of light available (daily photon irradiance), nutrient and water availability, temperature, and plant age/size. However, two of these, water availability and temperature, tended to have large effects only at extremes - very low temperatures, and either strong water deficits or waterlogging conditions. Thus, for most plants, light intensity and nutrient availability seem to be the primary factors driving carbon acquisition and biomass allocation. While Poorter's review covered a huge number of studies, 
unfortunately they could not cover physiological mechanisms in great detail. The purpose of this review is to cover some of the mechanisms controlling plant performance, particularly in the areas of photon capture by shoots and resource acquisition by roots, with a focus on grasses.

Grasses (family Poaceae) are a plant group of unique importance in agriculture. Grasses contribute more than half the calories consumed worldwide - both directly, as cereals, and as forage grasses that form the basis for the production of meat and milk worldwide [4]. Thus, a complete understanding of the factors determining the productivity of grass plants is of fundamental importance in meeting the food needs of the growing human population. Cultivated and semi-natural grasslands cover an area estimated at 52 million $\mathrm{km}^{2}$ [5], and account for approximately $15 \%$ of global primary productivity [4]. Grass architecture is based around a tiller axis comprised of a stack of phytomers with an apical meristem responsible for the production of new phytomers. Each phytomer has the capacity to produce one leaf, one tiller, and one or more roots. The tiller axis of vegetative grasses is generally small, and is often located around ground level, while the leaves grow from the base, as adaptations to prevent grazing damage to the meristems. Perennial ryegrass (Lolium perenne L.) has on average three leaves per tiller, with the initiation of new leaves coinciding with the senescence of the fourth leaf [6], while cereal grasses may have a much higher number of leaves.

Under competitive conditions, we expect plants to pursue a strategy where they use resources such as $\mathrm{N}$ and water to maximise growth and ultimately reproduction. Photoassimilates represent both the substrate for growth, and also energy storage for biochemical activities. The partitioning of these resources can have significant implications for plant productivity. For example, generally in grasses, around $80 \%-85 \%$ of plant biomass is partitioned to aboveground organs, such as leaves and stems, with $15 \%-20 \%$ allocated to roots. However, root mass allocation can be significantly affected by nutrient or light availability [3], with greater carbon allocation to the root system under low nutrient, high-light conditions. Even within the root system, the distribution of roots is frequently non-uniform, with localized root proliferation common in nutrient rich patches [7]. This proliferation produces root biomass in excess of that required to fully exploit the nutrient-rich patch, but is thought to increase nutrient capture rates in competitive environments, allowing such plants to outcompete those producing fewer roots, and thus come to dominate the ecosystem. It is worth stressing that the optimal biomass allocation will depend heavily on environmental constraints.

Thornley [8] developed an early model of vegetative plant growth and biomass allocation based upon carbon and nitrogen uptake and assimilation (Figure 1). Thornley's model holds that carbon fixed in the shoot is either used in the shoot or transported to the roots. Similarly, nitrogen absorbed by the roots can either be used directly in situ, or transported to the shoot. Although over the subsequent decades many more complex models have been developed [9-14], Thornley's model provides a clear, simple starting point from which to develop a more comprehensive understanding of biomass allocation in grasses. Within each compartment, carbon can be used either for maintenance or growth [15]. In the case of roots, carbon from the stem can be respired to provide energy for metabolic processes such as nutrient uptake and assimilation, or used in growth to explore the soil for further nutrients. Meanwhile, nitrogen in excess of that required by roots can be transported to the shoots for use there. Thus, in order to understand the partitioning of carbon within plants, we need to understand the factors which determine the size of the carbon/nitrogen pool and its usage in each organ. While quantitative descriptions of factors driving 
carbon allocation are becoming increasingly robust [3], there remains much to be done on understanding the underlying mechanisms in context. This paper aims to outline some of these processes.

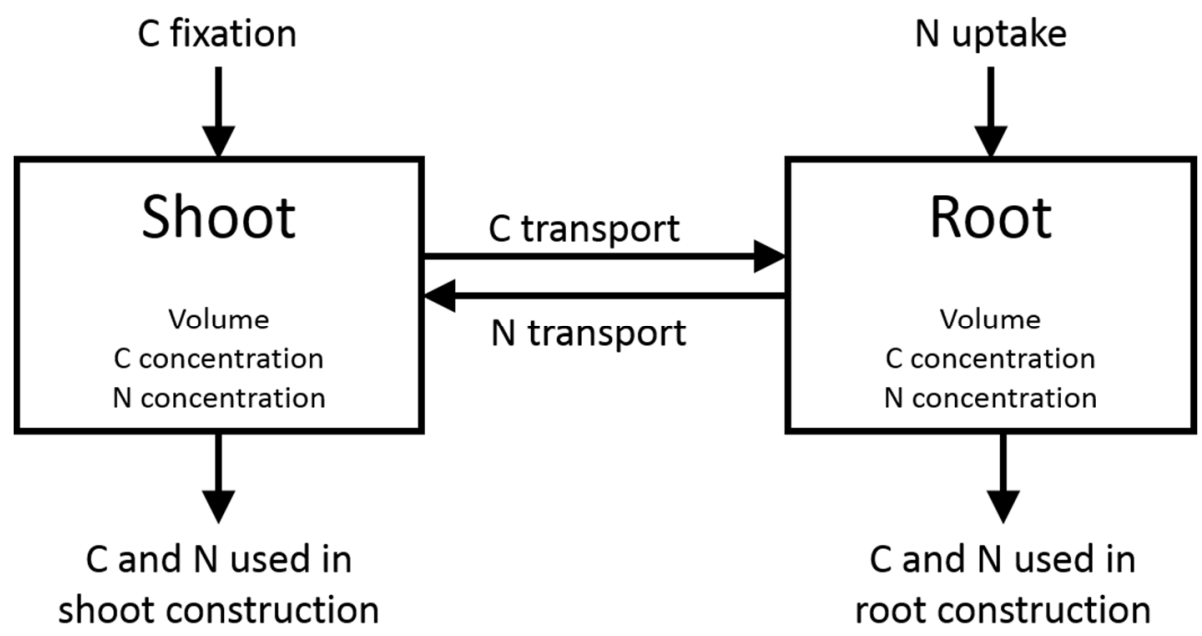

Figure 1. Two pool model of shoot and root growth. $\mathrm{C}$ and $\mathrm{N}$ status in each pool influences the volume of the pool. Adapted from [8].

\section{Carbon Fixation}

Given the primacy of photosynthesis in plant growth, it seems logical to first discuss factors influencing photosynthetic rate. However, given the size and complexity of the subject area, this is not intended to be a comprehensive analysis of photosynthesis, or of the factors controlling photosynthetic rates. Rather, the goal is to briefly explore a few of the more important factors, first on an individual plant basis, and then for competing plants in a later section.

At a biochemical level, the inefficiencies of $\mathrm{C}_{3}$ photosynthesis are well understood, and mainly center on the enzyme Rubisco [16]. The $\mathrm{CO}_{2}$ fixing enzyme, ribulose-1,5-bisphosphate carboxylase/oxygenase (Rubisco; EC4.1.1.39), has a very low catalytic efficiency; thus requiring the investment of $20 \%-30 \%$ of leaf nitrogen in Rubisco [17]. Given its inefficiency, and the relatively high proportion of leaf nitrogen for which Rubisco accounts, a strong positive correlation between photosynthetic rates and leaf nitrogen concentration has been noted [18,19]. As we shall discuss, this requirement for high concentrations of Rubisco in photosynthesizing leaves limits productivity, and has profound implications for plant form and productivity.

Photorespiration is the process by which Rubisco fixes oxygen rather than $\mathrm{CO}_{2}$, with the resulting production of $\mathrm{CO}_{2}$ and ammonia, and represents a second major inefficiency of $\mathrm{C}_{3}$ photosynthesis - and thus plant productivity — with up to one-third of light energy intercepted by the plant used in photorespiration. Photosynthesis and photorespiration are competitive, with an increase in $\mathrm{CO}_{2}$ or a decrease in $\mathrm{O}_{2}$ having equivalent effects of increasing carbon fixation. Indeed, classical studies show that growing Phaseolus vulgaris L. at reduced oxygen levels led to a $40 \%$ increase in photosynthetic $\mathrm{CO}_{2}$ uptake [20], while a $30 \%$ increase in grain yield was noted in rice plants grown at elevated $\mathrm{CO}_{2}$ [21]. Thus, it is generally assumed that increasing atmospheric $\mathrm{CO}_{2}$ levels will likewise lead to a decrease in photorespiration, and an increase in plant productivity. However, recent evidence suggests that malate 
formed during photorespiration is an important source of energy for the reduction of nitrate to nitrite - the first step in nitrate assimilation. Free air carbon dioxide enrichment (FACE) experiments suggest that future increases in atmospheric $\mathrm{CO}_{2}$ levels may suppress photorespiration, leading to grain protein levels between $7 \%$ and $10 \%$ lower than current conditions in $\mathrm{C}_{3}$ plants-with negative consequences for human nutrition and health globally [22,23]. However, this is strongly species-specific; in loblolly pine (Pinus taeda L.) saplings fed nitrate as their sole $\mathrm{N}$ source, $\mathrm{CO}_{2}$ enrichment led to a suppression of growth compared to plants fed ammonium, while in the same study, neither elevated $\mathrm{CO}_{2}$ levels nor nitrogen form had much of an effect on wheat (Triticum aestivum L.) growth [24]. While some studies have demonstrated acclimatory decreases in leaf photosynthesis as a result of elevated $\mathrm{CO}_{2}$ levels [25], others have noted increases in leaf photosynthetic rates [26], which may be linked to decreased stomatal conductance and improved water use efficiency. Clearly there remain significant questions about the photosynthetic and growth responses in $\mathrm{C}_{3}$ grasses, and the importance of elevated $\mathrm{CO}_{2}$ to future productivity.

$\mathrm{C}_{4}$ plants use a biochemical pump to increase the $\mathrm{CO}_{2}$ concentration around Rubisco, thus suppressing photorespiration. $\mathrm{C}_{4}$ Rubisco has carboxylation rates up to double those of $\mathrm{C}_{3}$ plants [27] with $\mathrm{C}_{4}$ plants achieving superior photosynthetic nitrogen use efficiencies $\left(\mathrm{CO}_{2}\right.$ fixed per unit nitrogen) due to their reduced $\mathrm{N}$ requirement for photosynthesis. Maize (Zea mays L.) and sorghum (Sorghum bicolor L.) are agronomically important $\mathrm{C}_{4}$ grasses, with both species used both for grain and as silages for animal fodder. However, given that approximately $46 \%$ of the estimated 10,000 grass species use $\mathrm{C}_{4}$ photosynthesis [28], there must be many other $\mathrm{C}_{4}$ grasses which would be suitable targets for improvement for forage, despite their generally low nutritive value. $\mathrm{C}_{4}$ photosynthesis has evolved at least 24 times in the grasses [29], and there are significant efforts currently to engineer $\mathrm{C}_{4}$ rice (Oryza sativa L.) with the goal of significant increases in grain yield [30]. $\mathrm{C}_{4}$ plants significantly increase the $\mathrm{CO}_{2}$ concentration around Rubisco, which in principle would allow the use of more efficient forms of Rubisco, such as those originating in cyanobacteria [31]. Cyanobacterial Rubisco has catalytic rates approximately four-times those of $\mathrm{C}_{3}$ plants, and might drive up carbon fixation rates and growth, or at least reduce $\mathrm{N}$ requirements for photosynthesis. This might be useful in crops destined for biofuel production, but the low tissue $\mathrm{N}$ levels would provide poor nutritive ability for animals. A further benefit of developing $\mathrm{C}_{4}$ agricultural species might be an improvement in stress tolerance. In sorghum, drought induced yield declines were reduced in plants grown under elevated $\mathrm{CO}_{2}$ conditions, suggesting that future increases in atmospheric $\mathrm{CO}_{2}$ conditions may alleviate drought stress, even in $\mathrm{C}_{4}$ plants [32].

Rubisco overexpressing (125\% of WT) rice plants exhibited $32 \%$ and $15 \%$ increased biomass when grown at 280 and $400 \mathrm{ppm} \mathrm{CO} 2$ respectively, but no difference at $1200 \mathrm{ppm}$. In the same study, Rubisco antisense plants (35\% of WT) exhibited significantly lower biomass levels, irrespective of $\mathrm{CO}_{2}$ level [33]. However, the reductions in relative growth rate in the antisense plants were small compared to the large decrease in leaf Rubisco levels. Clearly Rubisco concentration and growth are inherently linked to the atmospheric $\mathrm{CO}_{2}$ levels. Increases in $\mathrm{CO}_{2}$ levels have been shown to cause a decrease in leaf Rubisco levels in Arabidopsis [34,35] and rice [36], although Rubisco contents in pea (Pisum sativum L.), spinach (Spinacia oleracea L.), and parsley (Petroselinum crispum Mill.) (all $\mathrm{C}_{3}$ ) are relatively unaffected by $\mathrm{CO}_{2}$ levels [37]. It has been hypothesized that decreased $\mathrm{N}$ investment in Rubisco may lead to an increase in photosynthetic nitrogen use efficiency, and greater biomass production [16]. In line with this, wheat $\left(\mathrm{C}_{3}\right)$ plants grown under elevated $\mathrm{CO}_{2}$ were taller, produced more tillers, had lower leaf area ratio (leaf 
area per unit shoot mass), and at high $\mathrm{N}$ availabilities, had relatively larger root systems than plants grown under control $\mathrm{CO}_{2}$ levels [38]. $\mathrm{CO}_{2}$ levels had no effect on maize $\left(\mathrm{C}_{4}\right)$ growth in the same experiment, perhaps suggesting that future increases in atmospheric $\mathrm{CO}_{2}$ levels may have a smaller effect on $\mathrm{C}_{4}$ plant morphology than for $\mathrm{C}_{3}$ plants. If these findings can be applied to forage grasses, reduced leaf area and protein content would suggest that increasing $\mathrm{CO}_{2}$ levels may lead to significant declines in forage quality in $\mathrm{C}_{3}$ grasses.

\section{Plant Morphology as a Partial Consequence of Photosynthetic $\mathbf{N}$ Requirement}

Plant $\mathrm{N}$ concentration decreases allometrically with plant size [39]. The minimum $\mathrm{N}$ concentration which allows maximum growth is termed the "critical $\mathrm{N}$ concentration", with plants grown at sub-optimal $\mathrm{N}$ levels exhibiting proportionately decreased growth rates. Although there are clear differences in critical $\mathrm{N}$ concentrations between $\mathrm{C}_{3}$ and $\mathrm{C}_{4}$ plants due to the lower $\mathrm{N}$ requirements of $\mathrm{C}_{4}$ plants, the relationship between plant size and $\mathrm{N}$ concentration can be found in both groups, with the primary factor appearing to be a decrease in "leafiness" through plant development [14]. As the plant grows, over time a greater proportion of biomass must be allocated to stems and other support material. Thus, the decrease in $\mathrm{N}$ concentration with age may reflect an increase in shaded or senescent leaves over time, or a shift in shoot to root ratio such that $\mathrm{C}$ fixation rates are higher than $\mathrm{N}$ uptake rates. Hikosaka and Terashima [40] demonstrated that the optimal allocation of $\mathrm{N}$ into photosynthetic components varies with light and nitrogen availability. Under high light conditions, high levels of Rubisco are required to maximise photosynthesis. However, as the leaf ages and transitions to a subordinate canopy position shaded by younger leaves, the optimal balance shifts towards the degradation of Rubisco and the remobilization of $\mathrm{N}$ to new leaves. These patterns are exacerbated in $\mathrm{N}$-deficient plants.

Given that there is a light gradient down the canopy, with older leaves shaded by younger leaves, plant nitrogen use efficiency can be increased by translocating $\mathrm{N}$ in excess of photosynthetic requirements from older, shaded leaves, to younger leaves which have an optimal canopy position [41]. Grasses undergo progressive senescence where the older leaves senesce and are replaced by younger leaves on a continual basis. Photosynthetic rates at ambient $\mathrm{CO}_{2}$ levels scale with leaf Rubisco content [42], which increases rapidly during leaf emergence, reaches a peak around full expansion, and declines through until senescence $[43,44]$. However, even under high exogenous supply, approximately half of the nitrogen for new leaf growth comes from the remobilization of leaf proteins including Rubisco from older leaves [45]. Thus, Rubisco represents a key juncture between carbon and nitrogen metabolic pathways. Rubisco retention in older leaves may increase the photosynthetic capacity of that leaf; however, particularly under $\mathrm{N}$ limiting conditions, carbon fixation might have been higher had the $\mathrm{N}$ been remobilized to younger leaves. In this case, maximising leaf photosynthesis may lead to a decrease in carbon fixation at the plant level. Thus, we expect a balance between the maintenance of leaf photosynthesis, and nitrogen remobilization to new tissues. Nitrogen remobilization is known to be important in supporting the development of new leaves - in Poa trivialis L. and Panicum maximum (Jacq.), despite removal of the exogenous $\mathrm{N}$ supply, new leaves continued to be produced using $\mathrm{N}$ remobilized from older organs [46]. Although some loss of $\mathrm{N}$ must be expected in senescent biomass, $\mathrm{N}$ remobilization is clearly important in determining plant productivity, with a recent paper demonstrating 
significantly reduced growth in mutant rice plants with reduced capacity for Rubisco degradation, particularly under $\mathrm{N}$ limiting conditions [47]. Thus, we can postulate an optimal leaf protein turnover rate which maximises canopy rather than leaf photosynthesis. Given the importance of $\mathrm{CO}_{2}$ availability to biomass production in Rubisco overexpressing rice, this optimum is likely environmentally modulated, or contingent on other factors, such as plant size. Development of grasses using high catalytic efficiency Rubisco may reduce the need for internal recycling of nitrogen, leading to a more uniform $\mathrm{N}$ allocation between leaves.

A recent paper [48] demonstrated a negative correlation between the maximum leaf Rubisco concentration and plant dry mass in glasshouse grown Lolium perenne plants. A second paper, comparing two long-leaved with two short-leaved L. perenne genotypes, presented evidence that leaf Rubisco content correlated strongly with leaf elongation duration, tiller weight, and leaf elongation rate, with a weaker correlation noted between leaf Rubisco content and plant dry mass [49]. However, these correlations disappeared when Rubisco levels were considered in terms of concentration rather than content. This suggests that leaf Rubisco concentration is relatively invariant, with plant productivity more strongly controlled by leaf size. If we assume that the maximum Rubisco concentration in leaf cells is essentially a constant, and that leaves grow in proportion to the available carbon and nitrogen resources, we might expect leaf size to be contingent upon photosynthetic rates and nitrogen remobilization within the plant as a whole.

In Fallopia japonica (Houtt.), as plant nitrogen content increases a greater proportion of biomass is allocated to leaves, while the specific leaf weight (leaf mass per unit area) decreases [10]. Even assuming that the net assimilation rate is invariant with $\mathrm{N}$ availability, this would necessarily lead to an increase in whole plant carbon gain and relative growth rate. Plant biomass has been shown to correlate strongly with intercepted radiation, with the gradient contingent on $\mathrm{N}$ availability [50]. In a study using short and long-leaved varieties of tall fescue, MacAdam et al. [51] demonstrated that while cell length and the relative leaf elongation rate were apparently genetically controlled, environmental factors such as temperature and light availability, as well as $\mathrm{N}$ supply, were important in determining the rate of leaf expansion. Plants receiving high N supply produced a significantly greater number of mesophyll cells, relative to epidermal cells [51]. This may yield thicker leaves, and given the importance of mesophyll cells for photosynthesis, might partially explain higher rates of photosynthesis in plants grown under high $\mathrm{N}$ conditions.

Canopy photosynthesis optimization models predict that under low light availabilities, canopies should have a low leaf area index (LAI; leaf area per unit ground area) which minimizes the self-shading of leaves. Under high light conditions, a greater number of leaves, and higher LAI, are predicted. However, as pointed out by Anten [52], optimized canopy models do not take into account the fact that LAIs which are optimal for canopies may not be evolutionarily stable for the individuals within those canopies, since low LAI plants can be outcompeted by plants with higher LAI, which have higher individual photosynthetic carbon gain. Thus, the optimal LAI for the plant is higher than the optimal value for the canopy [53]. However, there must similarly be a maximum LAI for plants, beyond which the carbon cost of increasing LAI is greater than the photosynthetic benefit. At a given LAI, in the absence of $\mathrm{N}$ fertilization, canopy photosynthesis in field grown tall fescue (Festuca arundinacea Schreb.) was 30\% reduced relative to well-fertilized plants. Since the measurements were controlled for LAI, these differences were attributed to a direct $\mathrm{N}$ effect on photosynthesis [54]. Grass growth is known 
to be strongly seasonal, and even N-deficient plants grown in spring or summer achieved significantly higher LAI than N-replete plants grown in autumn [55]. Presumably this results from a combination of low temperature, which limits leaf elongation rate [56], and reduced day-length and light intensity limiting carbon fixation. Taken together, these results suggest that nitrogen availability directly influences shoot growth via LAI, with photosynthetic declines resulting from $\mathrm{N}$-deficiency important only under otherwise optimal conditions.

Along with absolute leaf area, specific leaf area (SLA; leaf area per unit dry mass) can also vary and is an important factor in determining plant photosynthetic performance. Anten and Hirose [57] demonstrated that in Xanthium canadense (Mill.), SLA decreased with increasing light intensity, independent of nutrient availability. Similar results were noted in Lolium perenne with comparatively low SLA $\left(160 \mathrm{~cm}^{2} / \mathrm{g}\right)$ at high light, and higher values $\left(500 \mathrm{~cm}^{2} / \mathrm{g}\right)$ at low light levels (RA Carnevalli, personal communication). Poorter and Evans [58] showed that plants with high SLA had similar photosynthetic rates to low SLA plants on an area basis, but higher rates on a unit mass basis. At lower light intensities, high SLA plants tended to have higher photosynthetic rates per unit nitrogen, due to a greater leaf area production.

\section{Nutrient and Water Availability}

Nitrogen deficiency is a major factor limiting the growth and yield of agronomically important plants, with inorganic $\mathrm{N}$ fertilizers used as a cost-effective method to increase crop yields globally [60]. Nutrient capture by roots is a significant cost for plants, both in terms of soil exploration by root production and the $\mathrm{C}$ costs of root activities, which includes both nutrient uptake and assimilation. However, plant $\mathrm{N}$ content has a primary role in determining whole plant photosynthetic potential, and thus photosynthesis and productivity, and $\mathrm{C}$ investment in roots can thus be seen as a method of maximising future photosynthesis. Given the necessary allometric relationships between leaf area and root biomass, correlations between plant $\mathrm{N}$ uptake and shoot growth have been confirmed [60].

Maximum plant growth rates will be achieved when the partitioning of biomass facilitates sufficient nutrient uptake rates to match the rate of carbon supply by photosynthesis [9]. Long-term shifts in canopy photosynthesis (e.g., due to seasonal changes in light availability) have been shown to strongly affect the availability of carbohydrates for the production of leaves, roots, and daughter tillers [61]. Thomas and Davies [62] demonstrated that while the shoot mass of Lolium perenne was relatively unaffected by shading, root mass was positively correlated with mean daily insolation. The ability to control biomass partitioning is typically considered to be an adaptive response either as a mechanism to maximise relative growth rates by increasing photosynthetic carbon supply, or as a result of a shift in the site of competition: at low $\mathrm{N}$ availabilities, plants compete for nitrogen via the roots, while at higher $\mathrm{N}$ levels, light capture becomes more important, and biomass is partitioned towards production of leaves. Conversely, Thomas and Sadras [63] have suggested that rather than being carbon limited, most plants have a carbon surplus, and they posit root growth as a mechanism to balance carbon influx with respiratory usage. However, as well as these evolutionary explanations, we should consider more physiological mechanisms for these phenomena. In nitrogen starved wheat plants, approximately equal proportions of the carbon transported to the roots are incorporated into biomass, respired, and translocated back to the shoot as amino acids [64]. As nitrogen is supplied to roots, we might assume that $\mathrm{C}$ demand will increase, as a result of 
the respiratory and C-skeleton costs of amino acid synthesis. Assuming $\mathrm{C}$ supply to the roots to be relatively invariant over the short term, this might lead to decreased allocation of carbon for root production. In line with this, Scheible et al. [65] noted that nitrate accumulation in tobacco shoots was accompanied by a decrease in root sugar content, and that root sugar content correlated with root growth. As exogenous $\mathrm{N}$ concentration increases further, despite the ability of plant root cells to store nitrate in the vacuole [66], given the finite size of root storage capacity, we start to see transport of nitrate to the shoots, where it would be assimilated and used directly [67].

Nitrogen uptake in plants scales with root length, and has a strong genetic component [68]. In nitrogen and phosphate deprived plants, roots proliferate in nitrate, ammonium or phosphate rich patches to maximise nutrient capture [69]. A reanalysis of Drew's data suggested that while all the available nitrate could have been captured without proliferation, it increased the rate of nitrate capture, which would be important for plants in competitive environments [7]. However, root proliferation may be more important for ions with low soil mobility, such as ammonium and phosphate. In Arabidopsis, nitrate was shown to increase the length but not the number of lateral roots [70]. However, application of other $\mathrm{N}$ sources did not stimulate lateral root elongation, suggesting that nitrate was acting as a signal molecule, and its effect on root elongation was not directly as a nutrient. Conversely, very high levels of $\mathrm{N}$ supply tended to retard root growth and branching [70]. Ammonium patches also cause root proliferation, although the roots are shorter and much more highly branched when provided ammonium compared with nitrate [71]. This indicates separate mechanisms for root proliferation by nitrate and ammonium, which may have a functional significance, since nitrate has a diffusibility around 10-times higher than ammonium in soil [72].

Nitrogen availability is known to affect the allocation of biomass to the shoots or roots. However, the $\mathrm{N}$ form is rarely considered. Zerihun et al. [73] noted that there are significantly different $\mathrm{C}$ costs associated with assimilating nitrate, ammonium, or glutamine, and that the physical location and time of assimilation could also have effects. For example, malate derived from photorespiration acts as a source of reducing power for nitrate, where assimilation occurs in the leaves during the light period, without significantly affecting carbon fixation rates [23]. $\mathrm{N}$ assimilation costs have been postulated to have significant effects on biomass partitioning, and indeed fast-growing grass species have been shown to have lower nutrient assimilation costs than slower growing grass species [74], although the data did not support this hypothesis in Phaseolus vulgaris [73]. The factors determining the relative cost of $\mathrm{N}$ assimilation remain poorly understood, and further research is required to explore the importance of $\mathrm{C}$-costs of nutrient assimilation in determining plant growth rate and productivity. Work in tobacco has suggested a strong positive relationship between shoot to root ratio and leaf nitrate concentration [65], however that relationship broke down under phosphate deficiency or when plants were supplied ammonium, rather than nitrate. Andrews et al. [75] conversely argued that protein concentration, rather than leaf nitrate levels, was primarily important in shoot growth rates. Furthermore, as well as abiotic factors noted here, root mass allocation can also be affected by biotic factors-hemiparasitic plant infection has been shown to cause an increase in host plant root mass allocation, presumably caused by nutrient abstraction [76].

It is generally understood that the majority of grass plant roots occur in the surface layers of the soil [77]. A well-developed root system has the capacity to mitigate local variability in resource variability, providing a continuous supply of water and nutrients to leaves, despite the heterogeneous 
nature of the soil environment. Plants require large amounts of water for photosynthesis, since drought suppresses stomatal aperture leading to the depletion of intercellular $\mathrm{CO}_{2}$ and increased photorespiration. Furthermore, carbohydrate accumulation in tissues during stress [78] presumably leads to a reduction in their availability for growth, and has been shown to cause feedback repression of photosynthesis in Phaseolus vulgaris [79]. Thus, plants growing in dry environments may suffer retarded growth as a result of insufficient water availability. Deep roots comprise approximately $30 \%$ of the grass root system, and help to maintain access to water even during drought conditions [80]. Huang and Fu [77] noted that in tall fescue, when the surface layer of soil was allowed to dry out but deeper soil had adequate water, carbon allocation to the shoot was decreased by more than $40 \%$, while root production increased in both the upper, drier layer, and the lower layer. Presumably the functional significance of this is to maximise water uptake; however, the physiological mechanism by which it is achieved remains unclear.

\section{Competition}

The leaf canopy is a dynamic system with a constant turnover of leaves, influenced by environmental conditions. Within a dense stand where plants are competing strongly for light, vertical growth of the plant would be an optimal strategy. However, in more open canopies, vertical growth increases LAI and self-shading. Thus tillering is a preferred strategy, as this increases the number of growing leaves, presumably facilitating a greater increase in whole plant growth rate than could be achieved by an increase in leaf elongation rate alone. Plant $\mathrm{C} / \mathrm{N}$ ratio is thought to be important in controlling tiller initiation, with nitrogen replete, carbon deficient Carex rostrata (Stokes.) plants producing significantly more daughter stems than carbon replete, nitrogen deficient plants [81]. Similarly, Davies [82] presented data showing a strong correlation between tiller number and nitrogen application in Lolium perenne, while Gautier et al. [83] demonstrated that shading caused a decrease in both leaf appearance rates and tiller formation. Conversely, as discussed previously, wheat plants grown under elevated $\mathrm{CO}_{2}$ conditions produced more tillers than plants grown under control conditions [38]. The red/far-red ratio (R/FR) of light reaching the base of the canopy is an important shade signal for plants, and mediates a range of plant responses such as increased apical dominance, accelerated flowering and early seed production, and reduced tiller formation. The R/FR of daylight is around 1.2, but this decreases in deep canopies as the red light is absorbed by chlorophyll, making R/FR a signal for canopy closure [84]. A recent paper, which imposed increased R/FR on wheat cultivars demonstrated a 13\%-23\% increase in the number of tillers produced [85], while reduced tillering was found in wheat plants grown at high densities or under shade conditions where R/FR was decreased to around 0.4 [86]. Similarly, Gautier et al. [83] demonstrated a decrease in tiller formation in Lolium perenne plants grown under reduced R/FR. R/FR ratio has also been suggested to be a factor in tiller senescence, where decreases in ground-level R/FR coincided with a decline in tiller number [87], although whether this is a causal relationship or simply a result of canopy closure remains unclear. Irrespective of the mechanism, the shift in growth strategy from the production of many stems (tillering) to the concentration of resources in fewer, larger stems as competition for light increases appears common in grasses.

Within grass canopies, we expect a negative relationship between plant density and mass [88]. At low planting densities, the growth of new tillers fills the space in the canopy, while at high densities plant dry weight decreases, presumably due to competitive effects. Using Lolium perenne plants sown at a 
range of differing densities, Lonsdale and Watkinson [89] reported that plant shoot dry mass followed a $-3 / 2$ relationship with plant density under high light conditions. However, when the plants were put under heavy shade conditions ( $83 \%$ reduction in light intensity) or when the tiller masses became very large, this relationship shifted from $-3 / 2$ to approximately -1 . It is thought that at high plant masses, the stand reaches a maximum yield with no further increase in stand mass possible [90]. The -1 slope suggests that at some point resource usage is maximised (e.g., light interception nears $100 \%$ for the canopy), leading to a zero-sum game, where an increase in resource use by one plant is necessarily at the expense of a competing plant. This raises the question of whether light attenuation places a maximum limit on the quantity of photosynthetically active biomass produced per unit area. More recent work suggests that rather than $-3 / 2$, the true relationship between plant mass and density follows a $-4 / 3$ slope [91].

In Matthew et al. [92], plots under low grazing intensity tended to have fewer, larger tillers, and a higher overall biomass. Plots grazed at higher intensities tended to have a greater number of smaller tillers. Grazing led to a more open canopy, presumably prompting tiller initiation and facilitating establishment. Under high light conditions, grazing is thought to have similar implications for plant morphology and yield as growth under low light conditions, due to the reduced leaf area for light interception. Clear seasonal differences in tiller density were apparent, with increased tiller numbers during the summer, suggesting that higher light levels in the summer may act as a substitute for a more open canopy in Lolium perenne. Interestingly, there was also seasonality in biomass per unit area for any given tiller density, which was explained by an increase in leaf area index. This suggests environmental factors, other than light, influence the maximum potential biomass. Temperature and light quality both seem to be viable candidates with low temperatures linked to decreased leaf appearance rates [93], although other factors such as water availability and nitrogen availability are also important.

Competition for light between plants promotes an increase in plant height. Taller plants must invest more carbon in support structures and less in leaves. Anten and Hirose [57] demonstrated than Xanthium canadense plants grown in stands invested a lower proportion of their mass in leaves than plants grown singly. Increased height allows increased access to light, but comes at the cost of carbon invested in stems. Thus, there must be an optimal plant height at which the $\mathrm{C}$ cost of additional stem production is greater than any increases in light interception and $\mathrm{C}$ fixation resulting from the increase in plant height. In stands where we have individuals of different species, or unrelated members of the same species, we would expect competitive pressures to drive individuals towards this, presumably environmentally influenced, maximum. However, the situation for clonal plants or tillers of an individual plant remains unclear. As covered earlier, the optimal LAI for an individual plant is higher than that for the canopy. Similarly, we might expect the optimal tiller number per plant to be higher than the optimal tiller density for the canopy. Clearly, excessive competition between multiple stems of a single plant would be disadvantageous for the plant, and we might expect to see a reduction of LAI towards the canopy optimum in clonal stands. On the other hand, limiting competitive effects might be difficult, as it would require the plant to be able to differentiate between tillers and other plants, and to communicate these differences internally. Little work has been conducted on the competitive pressures between tillers in a single plant. 


\section{Carbon Allocation}

Photoassimilate is the major substrate for plant growth, thus it is impossible to understand plant performance without a thorough understanding of the factors determining assimilate transport and partitioning [94]. Phloem is the primary pathway for the transport of carbohydrates from the sites of assimilation (i.e., mature leaves) to the sites of utilization (growth and respiration). However, the direct study of phloem is difficult, requiring the use of radioisotopes with rapid decay rates $\left(\mathrm{e} . \mathrm{g} .,{ }^{11} \mathrm{C}\right)$ and expensive equipment, such as positron imaging systems. In the majority of studies, the allocation of carbon to organs is studied using stable or radioisotopes with slower decay rates (e.g., ${ }^{13} \mathrm{C}$ or $\left.{ }^{14} \mathrm{C}\right)$, and although this is less direct it has allowed us to build models of carbon allocation within plants.

Carbon flux rates are generally assumed to be a function of the difference in concentration between $\mathrm{C}$-sources such as photosynthesizing leaves, and sinks such as growing leaves, roots or seeds $[11,13]$. While source strength is fairly easily understood as deriving from photosynthetic $\mathrm{C}$ fixation, sink strength is a less well-defined concept. One way to think about it may be as the capacity of phloem companion cells in the proximity of a meristem to unload sugars. An upper limit may be established by the ability of cells to use carbon during division, expansion and differentiation [13]. ${ }^{14} \mathrm{C}$ labelling studies show the preferential allocation of carbon to young developing roots, with the oldest roots receiving little from the shoots [95]. Given that the older, established roots have a greater biomass and more apical meristems, we might postulate that they have a greater sink capacity than the younger roots. If $\mathrm{C}$ allocation is sink-driven, it would be difficult to understand this allocation. It has been hypothesized that the utilization of photoassimilates by young roots close to the shoot renders the supply insufficient for more distant sinks (C Matthew, personal communication), or it may be that transport resistance between the leaf and the root apical meristem is a key factor determining carbon allocation. Assuming that transport of assimilates through the phloem follows Poiseuille's law, the resistance of C flow down the root would be proportional to the root's length. Thus, the root tips of longer roots might be expected to receive less photoassimilate than younger, shorter roots, due to their length rather than their age or axial position. Phloem sap viscosity is known to be an important limitation to $\mathrm{C}$ export from photosynthesizing Pinus sylvestris L. leaves [96], suggesting a similar phenomenon might occur in grass roots, although this remains speculative.

In Lolium perenne and Paspalum dilatatum (Poir.), 48\%-64\% of the carbon incorporated into new tissues was assimilated within the preceding $24 \mathrm{~h}$ [97]. In contrast, for nitrogen, these figures were $3 \%-17 \%$, with over $80 \%$ of $\mathrm{N}$ having been supplied by an intermediate storage pool. This intermediate storage pool undoubtedly refers to internal remobilization from senescing to newly growing organs. Carbon older than 2-3 days contributed little to new tissue growth, and shaded plants tended to grow more slowly, further reinforcing the close linkage between photosynthesis and growth rate. Short-term labelling studies show that photoassimilates can travel 2-3 cm per minute in Vicia faba L. [98], potentially allowing $C$ to reach leaf growth zones within 10 to $20 \mathrm{~min}$ from assimilation, and reinforcing the close linkage between photosynthesis and growth. Similarly to new tissues, when we look at root exudates, we find that approximately $58 \%$ of the $\mathrm{C}$ in $L$. perenne root exudates derives from recent assimilation [99].

Reciprocal translocation of $\mathrm{C}$ and $\mathrm{N}$ between tillers appears to be common, and is a potential mechanism by which mature tillers can support the growth and development of daughter tillers. Daughter 
tillers represent a potential $\mathrm{C}$ source for root growth and development [100]. However, the degree of resource sharing between tillers appears to vary between species and varieties, and presumably has an environmental component. In Panicum maximum, young daughter tillers have a tight vascular connection with their parent and a high degree of photoassimilate sharing is apparent, while secondary tillers (those connected to primary tillers) receive virtually no carbon from the parent stem, suggesting a low degree of vascular continuity [100]. In Poa trivialis, removal of an exogenous N supply effectively stopped $\mathrm{N}$ remobilization from mature leaves on the main stem to developing daughter tillers [46]. Clearly, tillering has important implications for plant productivity, although factors influencing the degree of resource sharing between the main stem and daughter tillers remain poorly understood. Furthermore, since each tiller can be split off and regenerate a whole plant, this raises a philosophical question about what constitutes the plant, and whether tillers which remain physically attached but have lost vascular connection can be meaningfully said to be the same plant.

It is generally understood that photosynthate partitioning is "local" in grasses, with upper leaves feeding the developing panicle in reproductive wheat plants, while lower leaves provide carbon for roots [101]. Carbon fixed by primary tillers was allocated first to the tiller itself, and secondly to main stem axial roots. However, carbon fixed by secondary tillers tended to be retained almost wholly in those tillers, with secondary tillers having little role in supporting main stem roots [101]. Work on the interaction between tillers of different ages within a plant are at a rudimentary level, and the balance between cooperation and competition between stems in a single plant as it develops remains completely unstudied, yet clearly of enormous importance. Osaki et al. [102] has pointed out the need for continued carbon investment in roots as the plant matures to maximise plant production. As grasses shift from vegetative to reproductive growth, we see a shift in the relative mass of leaves as carbon is allocated to stem elongation [3]. As the tillers increase in size, it seems likely that the shading of older leaves deeper in the canopy leads to a decline in carbon flux to the roots and therefore root activity, and perhaps the characteristic drying out we see in maturing cereal crops.

\section{Conclusions}

While much progress has been made over the last few decades in certain aspects, a great deal of work remains to be done before a comprehensive understanding of the factors controlling plant carbon allocation and plant productivity emerges. Key questions remain regarding the potential diminishment of $\mathrm{C}_{3}$ grass nutritive value under elevated $\mathrm{CO}_{2}$ conditions, and whether $\mathrm{C}_{4}$ plants will gain in importance as a target for forage plant improvement due to their potentially superior stress tolerance under high $\mathrm{CO}_{2}$ conditions. Recent work in rice has unequivocally demonstrated the importance of Rubisco turnover for plant growth, and that Rubisco turnover rates appear to have a high degree of genetic variability. However, linking leaf behaviour to whole plant performance has yielded little so far, and a more comprehensive approach to the problem seems necessary. The factors controlling tiller formation remain unclear, with most studies in the area relying heavily on correlation and few causative links demonstrated. Both red/far-red ratio and carbon/nitrogen balance appear important, but there is little clarity on the relative importance of these factors. Similarly, the drivers of carbon allocation to differing classes of roots remains a key question, which will probably require a combined modelling/experimental approach. Finally, cooperation and competition between tillers in a single plant for $\mathrm{N}$ and $\mathrm{C}$ remains 
almost completely unexplored, and represents an important avenue for future research efforts. Although many questions remain, much work has been done since the heyday of forage research in the 1970s. We continue to hope that a more complete understanding of plant carbon metabolism will help us develop higher-yielding, fertilizer-efficient plants.

\section{Acknowledgements}

The author would like to thank the editor and two anonymous referees for their insightful comments.

\section{Conflicts of Interest}

The author declares no conflict of interest.

\section{References}

1. Kruger, E.L.; Volin, J.C. Reexamining the empirical relationship between plant growth and leaf photosynthesis. Funct. Plant Biol. 2006, 33, 421-429.

2. Wright, I.J.; Reich, P.B.; Westoby, M.; Ackerly, D.D.; Baruch, Z.; Bongers, F.; Cavender-Bares, J.; Chapin, T.; Cornelissen, J.H.C.; Diemer, M.; et al. The worldwide leaf economics spectrum. Nature 2004, 428, 821-827.

3. Poorter, H.; Niklas, K.J.; Reich, P.B.; Oleksyn, J.; Poot, P.; Mommer, L. Biomass allocation to leaves, stems and roots: Meta-analysis of interspecific variation and environmental control. New Phytol. 2012, 193, 30-50.

4. Raven, J.A.; Thomas, H. Grasses. Curr. Biol. 2010, 20, R837-R839.

5. Rehuel, D.; de Cauwer, B.; Cougnon, M. The role of forage crops in multifunctional agriculture. In Fodder Crops and Amenity Grasses; Boller, B., Posselt, U.K., Veronesi, F., Eds.; Springer-Verlag: New York, NY, USA, 2010; pp. 1-12.

6. Fulkerson, W.J.; Donaghy, D.J. Plant-soluble carbohydrate reserves and senescence-key criteria for developing an effective grazing management system for ryegrass-based pastures: A review. Aust. J. Exp. Agric. 2001, 41, 261-275.

7. Robinson, D. Resource capture by localized root proliferation: Why do plants bother? Ann. Bot. 1996, 77, 179-185.

8. Thornley, J.H.M. A balanced quantitative model for root:shoot ratios in vegetative plants. Ann. Bot. 1972, 36, 431-441.

9. Robinson, D. Compensatory changes in the partitioning of dry matter in relation to nitrogen uptake and optimal variations in growth. Ann. Bot. 1986, 58, 841-848.

10. Hirose, T. A vegetative plant growth model: Adaptive significance of phenotypic plasticity in matter partitioning. Funct. Ecol. 1987, 1, 195-202.

11. Durand, J.-L.; Varlet-Grancher, C.; Lemaire, G.; Gastal, F.; Moulia, B. Carbon partitioning in forage crops. Acta Biotheor. 1991, 39, 213-224.

12. Sheehy, J.E.; Gastal, F.; Mitchell, P.L.; Durand, J.-L.; Lemaire, G.; Woodward, F.I. A nitrogen-led model of grass growth. Ann. Bot. 1996, 77, 165-177. 
13. Lemaire, G.; Millard, P. An ecophysiological approach to modelling resource fluxes in competing plants. J. Exp. Bot. 1999, 50, 15-28.

14. Gastal, F.; Lemaire, G.; Durand, J.-L.; Louarn, G. Quantifying crop responses to nitrogen and avenues to improve nitrogen-use efficiency. In Crop Physiology, Applications for Genetic Improvement and Agronomy, 2nd ed.; Sadras, V.O., Calderini, D., Eds.; Academic Press/Elsevier: Oxford, UK, 2015; pp. 159-206.

15. Amthor, J.S. The role of maintenance respiration in plant growth. Plant Cell Environ. 1984, 7, 561-569.

16. Yamori, W.; Irving, L.J.; Adachi, S.; Busch, F.A. Strategies for optimizing photosynthesis with biotechnology to improve crop yield. Handb. Photosynth. 2016, in press.

17. Galmés, J.; Kapralov, M.V.; Andralojc, P.J.; Conesa, M.À.; Keys, A.J.; Parry, M.A.J.; Flexas, J. Expanding knowledge of the Rubisco kinetics variability in plant species: Environmental and evolutionary trends. Plant Cell Environ. 2014, 37, 1989-2001.

18. Evans, J.R. Photosynthesis and nitrogen relationships in leaves of $\mathrm{C}_{3}$ plants. Oecologia 1989, 78, 9-19.

19. Makino, A.; Sato, T.; Nakano, H.; Mae, T. Leaf photosynthesis, plant growth and nitrogen allocation in rice under different irradiances. Planta 1997, 203, 390-398.

20. Parkinson, K.J.; Penman, H.L.; Tregunna, E.B. Growth of plants in different oxygen concentrations. J. Exp. Bot. 1974, 25, 132-145.

21. Yoshida, S. Effects of $\mathrm{CO}_{2}$ enrichment at different stages of panicle development on yield components and yield of rice (Oryza sativa L.). Soil Sci. Plant Nutr. 1973, 19, 311-316.

22. Myers, S.S.; Zanobetti, A.; Kloog, I.; Huybers, P.; Leakey, A.D.B.; Bloom, A.J.; Carlisle, E.; Dietterich, L.H.; Fitzgerald, G.; Hasegawa, T.; et al. Increasing $\mathrm{CO}_{2}$ threatens human nutrition. Nature 2014, 510, 139-142.

23. Bloom, A.J. The increasing importance of distinguishing among plant nitrogen sources. Curr. Opin. Plant Biol. 2015, 25, 10-16.

24. Bloom, A.J.; Asensio, J.S.R.; Randall, L.; Rachmilevitch, S.; Cousins, A.B.; Carlisle, E.A. $\mathrm{CO}_{2}$ enrichment inhibits shoot nitrate assimilation in $\mathrm{C}_{3}$ but not $\mathrm{C}_{4}$ plants and slows growth under nitrate in C3 plants. Ecology 2012, 93, 355-367.

25. Sicher, R.C.; Bunce, J.A. Relationship of photosynthetic acclimation to changes of Rubisco activity in field grown winter wheat and barley during growth in elevated carbon dioxide. Photosynth. Res. 1997, 52, 27-38.

26. Garcia, R.L.; Long, S.P.; Wall, G.W.; Osborne, C.P.; Kimball, B.A.; Nie, G.Y.; Pinter, P.J., Jr.; LaMorte, R.L.; Wechsung, F. Photosynthesis and conductance of spring-wheat leaves: Field response to continuous free-air atmospheric $\mathrm{CO}_{2}$ enrichment. Plant Cell Environ. 1998, 21, $659-669$.

27. Ghannoum, O.; Evans, J.R.; Chow, W.S.; Andrews, T.J.; Conroy, J.P.; von Caemmerer, S. Faster Rubisco is the key to superior nitrogen use efficiency in NADP-Malic enzyme relative to NAD-Malic enzyme C4 grasses. Plant Physiol. 2005, 137, 638-650.

28. Sage, R.F.; Li, M.; Monson, R.K. The taxonomic distribution of $\mathrm{C}_{4}$ photosynthesis. In $\mathrm{C}_{4}$ Plant Biology; Sage, R.F., Monson, R.K., Eds.; Academic Press, San Diego, USA, 1999; pp. 551-584. 
29. Studer, R.A.; Christin, P.A.; Williams, M.A.; Orengo, C.A. Stability-activity tradeoffs constrain the adaptive evolution of RubisCO. Proc. Natl. Acad. Sci. USA 2014, 111, 2223-2228.

30. Von Caemmerer, S.; Quick, W.P.; Furbank, R.T. The development of $\mathrm{C}_{4}$ rice: Current progress and future challenges. Science 2012, 336, 1671-1672.

31. Lin, M.T.; Occhialini, A.; Andralojc, P.J.; Parry, M.A.J.; Hanson, M.R. A faster Rubisco with potential to increase photosynthesis in crops. Nature 2014, 513, 547-550.

32. Conley, M.M.; Kimball, B.A.; Brooks, T.J.; Pinter, P.J., Jr.; Hunsaker, D.J.; Wall, G.W.; Adam, N.R.; LaMorte, R.L.; Matthias, A.D.; Thompson, T.L.; et al. $\mathrm{CO}_{2}$ enrichment increases water-use efficiency in sorghum. New Phytol. 2001, 151, 407-412.

33. Sudo, E.; Suzuki, Y.; Makino, A. Whole plant growth and N utilization in transgenic rice plants with increased or decreased Rubisco content under different $\mathrm{CO}_{2}$ partial pressures. Plant Cell Physiol. 2014, 55, 1905-1911.

34. Cheng, S.H.; Moore, B.D.; Seemann, J.R. Effects of short and long-term elevated $\mathrm{CO}_{2}$ on the expression of ribulose-1,5-bisphosphate carboxylase/oxygenase genes and carbohydrate accumulation in leaves and Arabidopsis thaliana (L.) Heynh. Plant Physiol. 1998, 116, 715-723.

35. Moore, B.D.; Cheng, S.H.; Sims, D.; Seemann, J.R. The biochemical and molecular basis for photosynthetic acclimation to elevated atmospheric $\mathrm{CO}_{2}$. Plant Cell Environ. 1999, 22, 567-582.

36. Seneweera, S.; Makino, A.; Hirotsu, N.; Norton, R.; Suzuki, Y. New insight into the photosynthetic acclimation to elevated $\mathrm{CO}_{2}$ : The role of leaf nitrogen and ribulose-1,5-bisphosphate carboxylase/oxygenase content in rice leaves. Environ. Exp. Bot. 2011, 71, 128-136.

37. Moore, B.D.; Cheng, S.H.; Rice, J.; Seemann, J.R. Sucrose cycling, Rubisco expression, and prediction of photosynthetic acclimation to elevated atmospheric $\mathrm{CO}_{2}$. Plant Cell Environ. 1998, 21, 905-915.

38. Hocking, P.J.; Meyer, C.P. Effects of $\mathrm{CO}_{2}$ enrichment and nitrogen stress on growth, and partitioning of dry matter and nitrogen in wheat and maize. Aust. J. Plant Physiol. 1991, 18, 339-356.

39. Gastal, F.; Lemaire, G. N uptake and distribution in crops: An agronomical and ecophysiological perspective. J. Exp. Bot. 2002, 53, 789-799.

40. Hikosaka, K.; Terashima, I. A model of the acclimation of photosynthesis in the leaves of $\mathrm{C}_{3}$ plants to sun and shade with respect to nitrogen use. Plant Cell Environ. 1995, 18, 605-618.

41. Anten, N.P.R.; Schieving, F.; Werger, M.J.A. Patterns of light and nitrogen distribution in relation to whole canopy carbon gain in $\mathrm{C}_{3}$ and $\mathrm{C}_{4}$ mono- and dicotyledonous species. Oecologia 1995, 101, 504-513.

42. Makino, A. Rubisco and nitrogen relations in rice: Leaf photosynthesis and plant growth. Soil Sci. Plant Nutr. 2003, 49, 319-327.

43. Mae, T.; Makino, A.; Ohira, A. Changes in the amounts of ribulose bisphosphate carboxylase synthesized and degraded during the life-span of rice life (Oryza sativa L.). Plant Physiol. 1983, 24, 1079-1086.

44. Irving, L.J.; Robinson, D. A dynamic model of Rubisco turnover in cereal leaves. New Phytol. 2006, 169, 493-504.

45. Mae, T.; Ohira, K. The relationship of nitrogen related to leaf growth and senescence in rice plants (Oryza sativa L.). Plant Cell Physiol. 1981, 22, 1067-1074. 
46. Santos, P.M.; Thornton, B.; Corsi, M. Nitrogen dynamics in the intact grasses Poa trivialis and Panicum maximum receiving contrasting supplies of nitrogen. J. Exp. Bot. 2002, 53, 2167-2176.

47. Wada, S.; Hayashida, Y.; Izumi, M.; Kurusu, T.; Hanamata, S.; Kanno, K.; Kojima, S.; Yamaya, T.; Kuchitsu, K.; Makino, A.; et al. Autophagy Supports Biomass Production and Nitrogen Use Efficiency at the Vegetative Stage in Rice. Plant Physiol. 2015, 168, 60-73.

48. Khaembah, E.N.; Irving, L.J.; Thom, E.R.; Faville, M.J.; Easton, H.S.; Matthew, C. Leaf Rubisco turnover in a perennial ryegrass (Lolium perenne L.) mapping population: Genetic variation, identification of associated QTL, and correlation with plant morphology and yield. J. Exp. Bot. 2013, 64, 1305-1316.

49. Khaembah, E.N.; Gastal, F.; Carre, S.; Irving, L.J.; Barre, P.; Matthew, C. Morphology and Rubisco turnover characteristics of perennial ryegrass breeding populations after two and four cycles of divergent selection for long or short leaf length. Crop Pasture Sci. 2013, 64, 687-695.

50. Bélanger, G.; Gastal, F.; Lemaire, G. Growth analysis of a tall fescue sward fertilised with different rates of nitrogen. Crop Sci. 1992, 6, 1371-1376.

51. MacAdam, J.W.; Volenec, J.J.; Nelson, C.J. Effects of nitrogen on mesophyll cell division and epidermal cell elongation in tall fescue leaf blades. Plant Physiol. 1989, 89, 549-556.

52. Anten, N.P.R. Optimal photosynthetic characteristics of individual plants in vegetation stands and implications for species coexistence. Ann. Bot. 2005, 95, 495-506.

53. Anten, N.P.R. Evolutionarily stable leaf area production in plant populations. J. Theor. Biol. 2002, 217, 15-32.

54. Gastal, F.; Bélanger, G. The effects of nitrogen fertilization and the growing season on photosynthesis of field-grown tall fescue (Festuca arundinacea Shreb.) canopies. Ann. Bot. 1993, 72, 401-408.

55. Bélanger, G.; Gastal, F.; Warembourg, F.R. Carbon balance of tall fescue (Festuca arundinacea Shreb.): Effects of nitrogen fertilization and the growing season. Ann. Bot. 1994, 74, 653-659.

56. Gastal, F.; Bélanger, G.; Lemaire, G. A model of the leaf expansion rate of tall fescue in response to nitrogen and temperature. Ann. Bot. 1992, 70, 437-442.

57. Anten, N.P.R.; Hirose, T. Biomass allocation and light partitioning among dominant and subordinate individuals in Xanthium canadense stands. Ann. Bot. 1998, 82, 665-673.

58. Poorter, H.; Evans, J.R. Photosynthetic nitrogen-use efficiency of species that differ inherently in specific leaf area. Oecologia 1998, 116, 26-37.

59. Andrews, M.; Raven, J.A.; Lea, P.J. Do plants need nitrate? The mechanisms by which nitrogen form affects plants. Ann. Appl. Biol. 2013, 163, 174-199.

60. Lemaire, G.; van Oosterom, E.; Sheehy, J.; Jeuffroy, M.H.; Massignam, A.; Rossato, L. Is crop N demand more closely related to dry matter accumulation or leaf area expansion during vegetative growth? Field Crops Res. 2007, 100, 91-106.

61. Hikosaka, K. Leaf canopy as a dynamic system: Ecophysiology and optimality in leaf turnover. Ann. Bot. 2005, 95, 521-533.

62. Thomas, H.; Davies, A. Effect of shading on the regrowth of Lolium perenne swards in the field. Ann. Bot. 1977, 42, 705-715.

63. Thomas, H.; Sadras, V.O. The capture and gratuitous disposal of resources by plants. Funct. Ecol. 2001, 15, 3-12. 
64. Lambers, H.; Simpson, R.J.; Beilharz, V.C.; Dalling, M.J. Translocation and utilization of carbon in wheat (Triticum aestivum). Physiol. Plant. 1982, 56, 18-22.

65. Scheible, W.R.; Lauerer, M.; Schulze, E.D.; Caboche, M.; Stitt, M. Accumulation of nitrate in the shoot acts as a signal to regulate shoot-root allocation in tobacco. Plant J. 1997, 11, 671-691.

66. Miller, A.J.; Fan, X.; Orsel, M.; Smith, S.J.; Wells, D.M. Nitrate transport and signalling. J. Exp. Bot. 2007, 58, 2297-2306.

67. Andrews, M.; Morton, J.D.; Lieffering, M.; Bisset, L. The partitioning of nitrate assimilation between root and shoot of a range of temperate cereals and pasture grasses. Ann. Bot. 1992, 70, 271-276.

68. Laperche, A.; Devienne-Barret, F.; Maury, O.; le Gouis, J.; Ney, B. A simplified conceptual model of carbon/nitrogen functioning for QTL analysis of winter wheat adaptation to nitrogen deficiency. Theor. Appl. Genet. 2006, 113, 1131-1146.

69. Drew, M.C. Comparison of the effects of a localized supply of phosphate, nitrate, ammonium and potassium on the growth of the seminal root system, and the shoot, in barley. New Phytol. 1975, $75,479-490$.

70. Zhang, H.; Jennings, A.; Barlow, P.W.; Forde, B.G. Dual pathways for regulation of root branching by nitrate. Proc. Natl. Acad. Sci. USA 1999, 96, 6529-6534.

71. Lima, J.E.; Kojima, S.; Takahashi, H.; von Wirén, N. Ammonium triggers lateral root branching in Arabidopsis in AMMONIUM TRANSPORTER1;3-dependent manner. Plant Cell 2010, 22, 3621-3633.

72. Raven, J.A.; Wollenweber, B.; Handley, L.L. A comparison of ammonium and nitrate as nitrogen sources for photolithotrophs. New Phytol. 1992, 121, 19-32.

73. Zerihun, A.; McKenzie, B.A.; Morton, J.D. Photosynthate costs associated with the utilization of different nitrogen-forms: Influence on the carbon balance of plants and shoot-root biomass partitioning. New Phytol. 1998, 138, 1-11.

74. Scheurwater, I.; Cornelissen, C.; Dictus, F.; Welschien, R.; Lambers, H. Why do fast- and slow-growing grass species differ so little in their rate of root respiration, considering the large differences in the rate of growth and ion uptake? Plant Cell Environ. 1998, 21, 995-1005.

75. Andrews, M.; Raven, J.A.; Lea, P.J.; Sprent, J.I. A role for shoot protein in shoot—Root dry matter allocation in higher plants. Ann. Bot. 2006, 97, 3-10.

76. Irving, L.J.; Cameron, D.D. You are what you eat: Interactions between root parasitic plants and their hosts. Adv. Bot. Res. 2009, 50, 87-138.

77. Huang, B.; Fu, J. Photosynthesis, respiration, and carbon allocation of two cool-season perennial grasses in response to surface soil drying. Plant Soil 2000, 227, 17-26.

78. Hare, P.D.; Cress, W.A.; van Staden, J. Dissecting the roles of osmolyte accumulation during stress. Plant Cell Environ. 1998, 21, 535-553.

79. Araya, T.; Noguchi, K.; Terashima, I. Effect of carbohydrate accumulation on photosynthesis differ between sink and source leaves of Phaseolus vulgaris L. Plant Cell Physiol. 2006, 47, 644-652.

80. Hamblin, A.; Tennant, D. Root length density and water uptake in cereals and grain legumes: How well are they correlated? Aust. J. Agric. Res. 1987, 38, 513-527. 
81. Saarinen, T.; Haansuu, P. Shoot density of Carex rostrate Stokes in relation to internal carbon:nitrogen balance. Oecologia 2000, 122, 29-35.

82. Davies, A. Changes in growth rate and morphology of perennial ryegrass swards at high and low nitrogen levels. J. Agric. Sci. 1971, 77, 123-134.

83. Gautier, H.; Varlet-Grancher, C.; Hazard, L. Tillering responses to the light environment and to defoliation in populations of perennial ryegrass (Lolium perenne L.) selected for contrasting leaf length. Ann. Bot. 1999, 83, 423-429.

84. Smith, H. Phytochromes and light signal perception by plants-An emerging synthesis. Nature 2000, 407, 585-591.

85. Toyota, M.; Tatewaki, M.; Morokuma, M.; Kusutani, A. Tillering responses to high red/far red ratio of four Japanese wheat cultivars. Plant Prod. Sci. 2014, 17, 124-130.

86. Evers, J.B.; Vos, J.; Andrieu, B.; Struik, P.C. Cessation of tillering in spring wheat in relation to light interception and red: Far-red ratio. Ann. Bot. 2006, 97, 649-658.

87. Sparkes, D.L.; Holme, S.J.; Gaju, O. Does light quality initiate tiller death in wheat? Eur. J. Agron. 2006, 24, 212-217.

88. Simons, R.G.; Davies, A.; Troughton, A. The effect of spacing on the growth of two genotypes of perennial ryegrass. J. Agric. Res. 1973, 80, 495-502.

89. Lonsdale, W.M.; Watkinson, A.R. Light and self-thinning. New Phytol. 1982, 90, 431-445.

90. Lonsdale, W.M. The self-thinning rule: Dead or alive? Ecology 1990, 71, 1373-1388.

91. Enquist, B.J.; Brown, J.H.; West, G.B. Allometric scaling of plant energetics and population density. Nature 1998, 395, 163-165.

92. Matthew, C.; Lemaire, G.; Sackville-Hamilton, N.R.; Hernandez-Garay, A. A modified self-thinning equation to describe size/density relationships for defoliated swards. Ann. Bot. 1995, 76, 579-587.

93. Davies, A.; Thomas, H. Rates of leaf and tiller production in young spaced perennial ryegrass plants in relation to soil temperature and solar radiation. Ann. Bot. 1983, 57, 591-597.

94. Minchin, P.E.H.; Lacointe, A. New understanding on phloem physiology and possible consequences for modelling long-distance carbon transport. New Phytol. 2005, 166, 771-779.

95. Matthew, C.; Kemball, W.D. Allocation of carbon-14 to roots of different ages in perennial ryegrass (Lolium perenne L.). In Proceedings of the XVIII International Grassland Congress, Calgary: Association Management Center, Section 7, Calgary, Canada, 8-19 June, 1997; pp. 1-2.

96. Nikinmaa, E.; Hölttä, T.; Hari, P.; Kolari, P.; Mäkelä, A.; Sevanto, S.; Vesala, T. Assimilate transport in phloem sets conditions for leaf gas exchange. Plant Cell Environ. 2013, 36, 655-669.

97. Lattanzi, F.A.; Schnyder, H.; Thornton, B. The sources of carbon and nitrogen supplying leaf growth. Assessment of the role of stores with compartmental models. Plant Physiol. 2005, 137, 383-395.

98. Matsuhashi, S.; Fujimaki, S.; Kawachi, N.; Sakamoto, K.; Ishioka, N.S.; Kume, T. Quantitative modeling of photoassimilate flow in an intact plant using the positron emitting tracer imaging system (PETIS). Soil Sci. Plant Nutr. 2005, 51, 417-423.

99. Thornton, B.; Paterson, E.; Midwood, A.J.; Sim, A.; Pratt, S.M. Contribution of current carbon assimilation in supplying root exudates of Lolium perenne measured using steady-state ${ }^{13} \mathrm{C}$ labelling. Physiol. Plant. 2004, 120, 434-441. 
100. Carvalho, D.D.; Irving, L.J.; Carnevalli, R.A.; Hodgson, J.; Matthew, C. Distribution of current photosynthate in two Guinea grass (Panicum maximum Jacq.) cultivars. J. Exp. Bot. 2006, 57, 2015-2024.

101. Osaki, M.; Shinano, T.; Yamada, M.; Yamada, S. Function of node unit in photosynthate distribution to root in higher plants. Photosynthetica 2004, 42, 123-131.

102. Osaki, M.; Morikawa, K.; Matsumoto, M.; Shinano, T.; Iyoda, M.; Tadano, T. Productivity of high yielding crops. III. Accumulation of ribulose-1,5-bisphosphate carboxylase/oxygenase and chlorophyll in relation to productivity of high yielding crops. Soil Sci. Plant Nutr. 1993, 39, 399-408.

(C) 2015 by the authors; licensee MDPI, Basel, Switzerland. This article is an open access article distributed under the terms and conditions of the Creative Commons Attribution license (http://creativecommons.org/licenses/by/4.0/). 